\title{
Trocar and Veress needle injuries during laparoscopy
}

\author{
M. Schäfer, ${ }^{1,2}$ M. Lauper, ${ }^{1}$ L. Krähenbühl ${ }^{1,2}$ \\ ' Swiss Association for Laparoscopic and Thoracoscopic Surgery (SALTS), Aarberg Hospital, Aarberg, Switzerland \\ ${ }^{2}$ Department of Visceral and Transplantation Surgery, University of Zürich, Ramistrasse, CH-8091 Zürich, Switzerland
}

Received: 25 January 2000/Accepted in final form: 27 June 2000/Online publication: 12 December 2000

\begin{abstract}
Background: Inadvertent lesions of the intraabdominal organs and vessels caused by trocars and Veress needles are rare but serious complications of laparoscopic surgery. Establishing the pneumoperitoneum is believed to be the most dangerous step.

Methods: The Swiss Association for Laparoscopic and Thoracoscopic Surgery (SALTS) prospectively collected the data on 14,243 patients undergoing various standard laparoscopic procedures between 1995 and 1997. This database was investigated with special regard to intraabdominal complications caused by trocars and Veress needles.

Results: There were 22 trocar and four needle injuries (incidence, $0.18 \%$ ). Nineteen lesions involved visceral organs; the remaining seven were vessel injuries. The small bowel was the single most affected organ (six cases), followed by the large bowel and the liver (three cases each). All vascular lesions, except for one laceration of the right iliac artery, occurred as venous bleeding of either the greater omentum or the mesentery. Fourteen trocars were inserted under direct vision. Nineteen trocar injuries were recognized intraoperatively; diagnoses of two small bowel and one bladder injuries were made postoperatively. Needle injuries were all diagnosed intraoperatively. Only five injuries could be repaired laparoscopically; the remaining lesions were repaired openly. Four patients underwent an open reoperation, and another patient needed five reoperations. There was one death $(4.0 \%)$.

Conclusions: Trocar and needle injuries are rare complications of laparoscopy. However, if not recognized intraoperatively and repaired immediately, they induce increased morbidity and mortality. Both open and closed establishment of the pneumoperitoneum are related to a potential danger of perforating lesions, but inserting the first trocar under direct vision allows early recognition and immediate repair.
\end{abstract}

Presented at the annual meeting of the Society of American Gastrointestinal Endoscopic Surgeons (SAGES), Atlanta, Georgia. USA 1 April 2000 Correspondence to: L. Krähenbühl
Key words: Laparoscopy - Complications - Trocar Veress needle - Open vs closed - Pneumoperitoneum Prospective study

The set-up phase of laparoscopy with the establishment of the pneumoperitoneum and creation of the working space is associated with the danger of perforating injuries caused by trocars and the spring-loaded (Veress) needle [3]. In particular, blind insertions of the Veress needle and/or the first trocar near the umbilicus are related to the inadvertent perforation of vessels and parenchymatous and hollow viscus organs. If those injuries remain unrecognized at the time of the initial laparoscopy, they generally cause severe complications and may contribute to an increase in overall morbidity. Nonetheless, many surgeons prefer to use the closed technique to establish the pneumoperitoneum because it is believed to be less time-consuming and to prevent gas leakage. The open (Hasson) technique has been reported to be safer and is therefore increasingly favored by many surgeons [10]. However, even blunt introduction of the first trocar under direct vision cannot fully prevent every iatrogenic injury $[3,8,17]$. According to reports in the literature, the incidence of trocar and needle injuries is low, ranging from $0.03 \%$ to $0.2 \%$; however, these complications may be underreported, and the true incidence may be even higher $[3,5,6,9,11,17]$.

The main purpose of this prospective study was to investigate the intraabdominal complications of trocar and Veress needle injuries during standard intra- and extraperitoeneal laparoscopic procedures performed at a large number of different institutions in Switzerland.

\section{Patients and methods}

Since 1995, the Swiss Association for Laparoscopic and Thoracoscopic Surgery (SALTS) has prospectively collected data from patients undergoing various laparoscopic procedures at 97 institutions that perform general surgery (university, county and district hospitals, and surgeons in private practice) in Switzerland. This database represents probably $>65 \%$ of all 
laparoscopic procedures performed annually in Switzerland. Due to the national health care system, there is no systematic registration of all laparoscopies performed annually. For every patient, $>130$ single itemsincluding personal records, ASA classification, indication for surgery, preoperative investigations, intraoperative findings, operative complications, conversion rate, postoperative morbidity, reoperation rate, and mortalitywere recorded on a specially designed computerized worksheet. Follow-up of the patients was performed either by the surgical institution or the general practitioner.

The data for 14,243 laparoscopic procedures performed between January 1995 and December 1997 were analyzed with special attention to needle and trocar injuries. All patients with these complications were identified. Their medical records, operative reports, and an additional questionnaire, which was sent to the referring surgical institution or the general practitioner to obtain further details and follow-up, were then carefully reviewed. If necessary, the institutions or general practitioner were visited by one of us to collect the missing data.

The definition of a trocar (T) or needle injury (NI) included any perforation or laceration of intra- and retroperitoneal structures and organs, such as vessels, parenchymatous organs, small and large bowel, bladder, mesentery, and greater omentum. Vascular injuries of the abdominal wall (e.g., epigastric vessels) were excluded.

In the closed technique, the abdominal wall is lifted by the operator and assistant. The peritoneal cavity is punctured blindly with the Veress needle, followed by both an aspiration and a drop test, which are performed routinely. Then the Veress needle is connected to the insufflator. Open introduction of the first trocar means that after the fascia is incised and lifted up with stay sutures, the peritoneum is opened and the blunt trocar is inserted.

Results are expressed as mean \pm standard deviation (SD) and range values.

\section{Results}

\section{Patients and surgical procedures}

There were 14,243 patients (6084 male and 8159 female; sex ratio $\mathrm{M} / \mathrm{F}, 0.7$ ) with a mean age of 51.4 years (range, $6-95 \mathrm{ys}$ ) at the time of the operation. Most of the patients $(90.3 \%)$ presented in a low-risk condition according to their ASA 1 and 2 classifications.

Cholecystectomy was the most frequently performed main procedure $(59.4 \%)$, followed by herniotomy (17.6\%) and appendectomy (11.8\%). Although fundoplication and colon resection are established procedures, they were rarely performed. Adhesiolysis was performed predominantly as an additional procedure to one of the other main interventions. Four of five laparoscopic procedures were elective operations, whereas the remaining procedures $(20.3 \%)$ were performed on an emergency basis. The patients' baseline data and the various types of surgical procedures are summarized in Table 1.

Twenty-five patients (eight male and 17 female) with a mean age of 58.7 years (range, 29-89; y, TI, 57.5; NI, 65.0 y) were found to have had an intraabdominal complication due to a trocar or needle injury. Since one patient had two trocar-related lesions, a total of $26 \mathrm{TI}$ and NI (incidence, $0.182 \%$ ) were analyzed. The characteristics of that patient group are shown in Table 2 . Fifteen patients $(60 \%)$ had had a least one previous abdominal operation; the other 10 either had had no prior abdominal surgery (nine patients) or their status was unknown (one patient). Three TI and one NI occurred after access to the peritoneal cavity had been attempted through a preexisting abdominal scar. Although most of the patients were moderately obese (mean BMI, 29.6 and $26.9 \mathrm{~kg} / \mathrm{m}^{2}$ ), the BMI ranged widely, from 19.0 to $45.4 \mathrm{~kg} / \mathrm{m}^{2}$.
Table 1. Patients and surgical procedures

\begin{tabular}{ll} 
No. of patients & 14,243 \\
M/F & $6084 / 8159$ \\
Sex ratio & 0.7 \\
Age (yr) & \\
Mean & 51.4 \\
Range & $6-95$ \\
Patient risk (\%) & \\
Low-risk (ASA 1 and 2) & 90.3 \\
High-risk (ASA 3 and 4) & 9.7 \\
Surgical procedures & \\
Main procedure (\%) & \\
Cholecystectomy & $8452(59.4)$ \\
Appendectomy & $1687(11.8)$ \\
Herniotomy & $2511(17.6)$ \\
Fundoplication & $272(1.9)$ \\
Colon resection & $352(2.5)$ \\
Others & $969(6.8)$ \\
Additional procedure & 1133 \\
Adhesiolyis & 79.3 \\
Elective operation (\%) & 20.3 \\
Emergency operation (\%) & $25(0.182)$ \\
Patients with trocar and needle injuries (\%) & \\
\hline
\end{tabular}

ASA, American Society of Anesthesiologists

Table 2. Characteristics of patients with trocar and Veress needle injuries

\begin{tabular}{|c|c|c|}
\hline & Trocar injuries & Needle injuries \\
\hline No. of patients & 21 & 4 \\
\hline $\mathrm{M} / \mathrm{F}$ & $7 / 14$ & $1 / 3$ \\
\hline \multicolumn{3}{|l|}{ Age $(\mathrm{yr})$} \\
\hline Mean & 57.5 & 65.0 \\
\hline Range & $29-89$ & $31-81$ \\
\hline \multicolumn{3}{|l|}{ Body mass index $\left(\mathrm{kg} / \mathrm{m}^{2}\right)$} \\
\hline Mean & 29.4 & 26.9 \\
\hline Range & $19.0-45.4$ & $26.0-27.6$ \\
\hline No. of lesions & $22^{a}$ & 4 \\
\hline Visceral type & 17 & 2 \\
\hline Vascular type & 5 & 2 \\
\hline \multicolumn{3}{|l|}{ Previous abdominal operations } \\
\hline Yes & 13 & 2 \\
\hline No & 7 & 2 \\
\hline Unknown & 1 & 0 \\
\hline \multicolumn{3}{|l|}{ Surgical procedures } \\
\hline Cholecystectomy & 12 & 3 \\
\hline Appendectomy & 1 & \\
\hline Herniotomy & 2 & \\
\hline Diagnostic laparoscopy & 3 & 1 \\
\hline Gastric banding & 1 & \\
\hline Colon resection & 1 & \\
\hline Tubal sterilization & 1 & \\
\hline Elective operations & 16 & 1 \\
\hline Emergency operations & 5 & 3 \\
\hline
\end{tabular}

${ }^{a}$ One patient had two injuries

The surgical procedures performed comprised 15 cholecystectomies $(60 \%)$, four diagnostic laparoscopies (16\%), and two transabdominal endoscopic hernia repairs $(8 \%)$. The remaining four procedures (appendectomy, gastric banding, colon resection, tubal sterilization) were each performed once. TI occurred in 16 cases $(76.2 \%)$ during elective laparoscopies, and five TI were incurred during emergency laparoscopic procedures. However, three of the four NI occurred during emergency operations. Only four TI and NI were caused by inexperienced surgeons ( $<50$ laparoscopies); the remaining 22 injuries were caused by laparoscopic 
Table 3. Trocar injuries

\begin{tabular}{|c|c|}
\hline \multicolumn{2}{|l|}{ Affected visceral organs $(n=17)$} \\
\hline Stomach & 1 \\
\hline Small bowel & 6 \\
\hline Large bowel & 2 \\
\hline Greater omentum & 2 \\
\hline Liver & 3 \\
\hline Bladder, penis & 2 \\
\hline Unknown & 1 \\
\hline \multicolumn{2}{|l|}{ Affected vascular structures $(n=5)$} \\
\hline Vessel of the mesentery & 2 \\
\hline Vessel of the greater omentum & 2 \\
\hline Vessel of the falciform ligament & 1 \\
\hline \multicolumn{2}{|l|}{ Trocar placement } \\
\hline Umbilicus & 8 \\
\hline Median-epigastric & 2 \\
\hline Median-suprapubic & 6 \\
\hline Left upper quadrant & 2 \\
\hline Left lower quadrant & 1 \\
\hline Right lower quadrant & 1 \\
\hline Unknown & 1 \\
\hline \multicolumn{2}{|l|}{ Trocar size } \\
\hline $5-\mathrm{mm}$ & 6 \\
\hline $10-\mathrm{mm}$ & 12 \\
\hline $12-\mathrm{mm}$ & 1 \\
\hline Unknown & 1 \\
\hline \multicolumn{2}{|l|}{ Trocar shape } \\
\hline Conical & 9 \\
\hline Sharp & 9 \\
\hline Unknown & 3 \\
\hline Trocar insertion under direct vision & 14 \\
\hline Hasson technique (first trocar) & 3 \\
\hline Insertion under camera control (second, third trocar) & 11 \\
\hline Blind trocar insertion & 8 \\
\hline Umbilicus (first trocar) & 6 \\
\hline Other localization & 2 \\
\hline Lesion recognized intraoperatively & 18 \\
\hline Lesion not recognized intraoperatively & 4 \\
\hline Small bowel & 2 \\
\hline Large bowel & 1 \\
\hline Bladder & 1 \\
\hline
\end{tabular}

surgeons with a large (51-100 laparoscopies) or even a very large (>100 laparoscopies) experience.

\section{Trocar injuries (Table 3)}

There were 17 lesions of visceral organs $(77.3 \%)$ and five vascular lesions $(22.7 \%)$. Hollow viscus organs were the most frequently affected (nine of 17 lesions). The small bowel was the most injured single organ (six cases), followed by the liver (three cases), the large bowel (two cases), the urogenital organs (two cases), and the greater omentum (two cases). There was one transmural laceration of the gastric wall, and one final lesion was not specified. Vascular lesions were restricted to venous bleeding; these occurred in the greater omentum (two cases) and the small bowel mesentery (two cases). Finally, there was one vascular lesion of a smaller vessel in the falciform ligament.

The insertion of umbilical trocars caused eight lesions, which were all of the visceral type. Six trocars were inserted blindly; the other two trocars were introduced openly (Hasson technique). Another six lesions occurred during trocar insertion into the suprapubic area. Two further TI were caused by epigastric trocar placement. The remaining five trocars were placed in four different abdominal locations

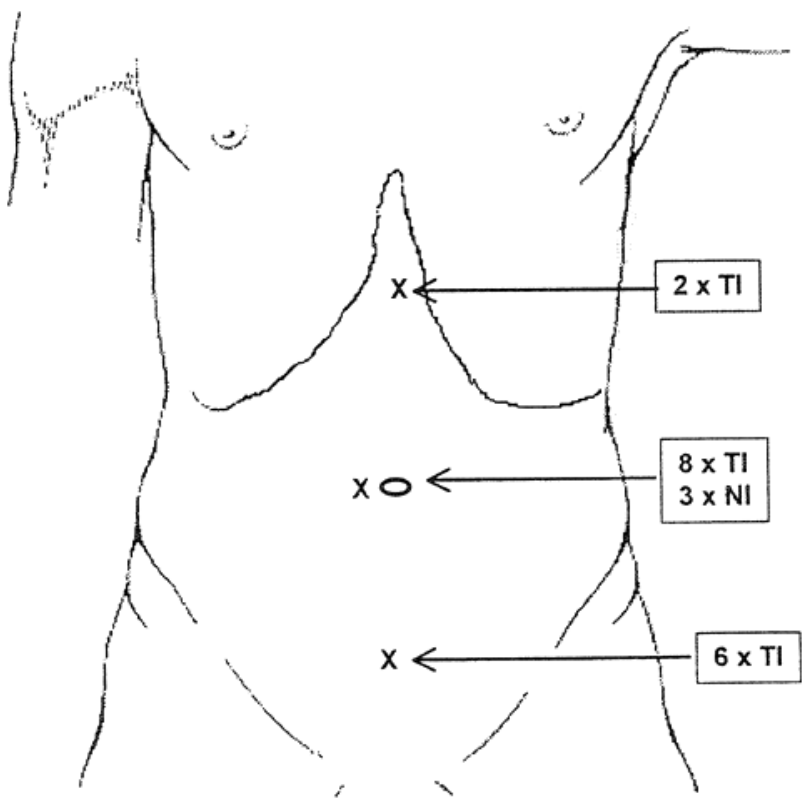

Fig. 1. Localization of trocar and needle injuries. Trocar and needle placement in the patient's midline, particulary at umbilical and suprapubic sites, is related to an increased risk of perforating lesion. In this series, 19 of 26 lesions $(73.1 \%)$ occurred after midline insertions of trocars and needles. TI. trocar injury; NI, needle injury.

(Fig. 1). The most frequently used trocar sizes were either $10-\mathrm{mm}(12 \mathrm{x})$ or 5-mm (six $\mathrm{x})$. Another TI was caused by a 12-mm trocar. For one TI, the trocar size was unknown. It was only partially possible to evaluate the trocar shape; neither so-called safety trocars nor the type (i.e., disposable vs reusable trocars) were specially investigated. However, in our series there were nine sharp (pyramidal introducer) and nine conical (non-cutting) trocars. For three TI, the trocar shape could not be determined. Eighth trocars $(38.1 \%)$ were inserted blindly after creation of the pneumoperitoneum as first trocars; another 10 trocars (14 TI, $61.9 \%$ ) were inserted under direct vision (second or third working trocar), and the remaining three trocars were inserted using the Hasson technique.

Although 18 lesions were recognized immediately after their occurrence, one perforation of the transverse colon was only found as an additional lesion in a patient who needed conversion due to a vascular lesion of the mesentery. The remaining three TI were diagnosed after a delay of 48-72 h. There were two perforations of the small bowel and one leakage of the bladder that were not discovered during the initial laparoscopic procedure.

\section{Veress needle injuries (Table 4)}

Only four intraabdominal NI (two visceral and two vascular lesions) were found in the whole patient group. There was one perforation of the transverse colon and one lesion that created an opening of the small bowel mesentery. Another patient had severe bleeding due to perforation of the right iliac artery. The other vascular lesion was due to an omental vein laceration. In all cases but one, the Veress needle had been introduced at the umbilicus (see Fig. 1). All four lesions were evident intraoperatively and were treated imme- 
Table 4. Veress needle injuries

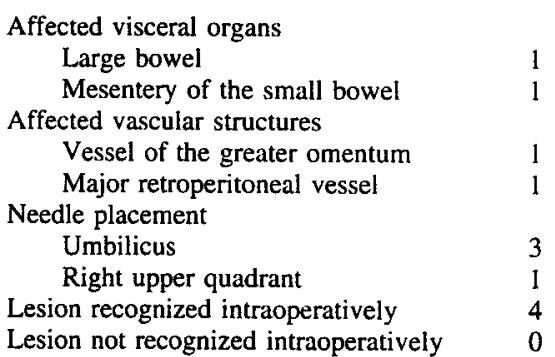

diately. Only the laceration of the small bowel mesentery was not repaired during the initial laparoscopy.

\section{Treatment and postoperative morbidity}

As shown in Table 5 and Table 6, only five of 23 (21.7\%) intraoperatively recognized $\mathrm{TI}$ and NI were repaired laparoscopically, whereas in 18 cases $(78.3 \%)$ conversion to an open approach was needed. One patient had a tear of the mesentery caused by an NI that was recognized intraoperatively, but no repair was done. He developed an obstructional ileus of the small bowel during the early postoperative course and underwent an open reoperation. Intraoperatively, an internal herniation of the small bowel through the mesenteric opening was found. Three patients who underwent a laparoscopic repair had a trocar-induced bleeding complication; hemostasis was achieved with either sutures, clips, or monopolar current. Two other patients had a superficial lesion of the anterior gastric wall and a tear of the greater omentum, respectively. The lesions were closed with laparoscopically applied sutures.

After conversion to an open approach, the repair of TI and NI was successful in all patients, except for two who had an insufficient closure of their small bowel perforation. Both patients developed severe peritonitis within $48-72 \mathrm{~h}$ of the initial laparoscopy. These two patients needed additional surgical interventions; in particular, one patient needed five reoperations.

Among the three TI discovered postoperatively, there were two small bowel perforations and one bladder injury. Development of severe peritonitis prompted an open reoperation, and the small bowel leakages were found. In both cases, after segmental small bowel resection and abdominal lavage, the further course was uneventful. The bladder laceration was treated conservatively by inserting an urinary catheter for 10 days. An 86-year-old female patient with preexisting liver cirrhosis, portal hypertension, and the histological finding of a gallbladder carcinoma (pT2) suffered a TI of the greater omentum that was repaired without any problems. However, during the postoperative course, she developed multiorgan failure and died.

Although the hospital stay ranged widely from 5 to 93 days, conversion to open repair prolonged the hospital stay for most of the patients. The mean hospital stay was 18 and 19 days for TI and NI, respectively.

\section{Discussion}

The aim of this prospective study was to assess the incidence, management, and outcome of trocar- and needle-
Table 5. Treatment, conversion rate, and postoperative morbidity

\begin{tabular}{|c|c|c|}
\hline & $\begin{array}{l}\text { Trocar } \\
\text { injuries } \\
(n=22)\end{array}$ & $\begin{array}{l}\text { Needle } \\
\text { injuries } \\
(n=4)\end{array}$ \\
\hline \multicolumn{3}{|l|}{ Treatment of intraoperatively recognized injuries } \\
\hline Laparoscopic repair & 4 & 1 \\
\hline Open repair & 15 & 2 \\
\hline No surgical treatment & 0 & 1 \\
\hline \multicolumn{3}{|l|}{ Treatment of postoperatively recognized injuries } \\
\hline Open repair & 2 & - \\
\hline No surgical treatment & 1 & - \\
\hline \multicolumn{3}{|l|}{ Conversion rate $(\%)$} \\
\hline All injuries & 68.2 & 50 \\
\hline Intraoperatively recognized injuries & 78.9 & 50 \\
\hline \multicolumn{3}{|l|}{ Postoperative complications } \\
\hline Wound infection & 1 & - \\
\hline Bile leakage & 1 & - \\
\hline Leakage of the small bowel, peritonitis & 4 & - \\
\hline Obstructive ileus & - & 1 \\
\hline Pneumonia & - & 1 \\
\hline Multiorgan failure & 2 & - \\
\hline Reoperations & 4 & 1 \\
\hline Mortality & 1 & 0 \\
\hline \multicolumn{3}{|l|}{ Hospital stay (days) } \\
\hline Mean & 18 & 19 \\
\hline Range & $8-93$ & $5-40$ \\
\hline
\end{tabular}

induced intraabdominal injuries incurred during standard laparoscopic procedures. There were $26 \mathrm{TI}$ and NI (incidence, $0.182 \%$ ) found among the 14,243 laparoscopies performed by the SALTS members between 1995 and 1997.

Establishing the pneumoperitoneum and inserting the working trocars remain the most crucial steps of laparoscopy. At least three different techniques are currently used to obtain laparoscopic access to the abdominal cavity. However, none of them entirely obviate the possibility of intraoperative complications caused by trocars and needles [ 3 , 8]. The closed technique is probably the most widely used method. The peritoneal cavity is punctured blindly with the Veress needle, followed by insufflation of the carbon dioxide [13]. Thereafter, the first trocar, which is often placed near the umbilicus, is introduced blindly into the peritoneal cavity. Alternatively, the first trocar can be inserted blindly without prior creation of the pneumoperitoneum [4, 18]. However, this modified closed technique has rarely been adopted by general surgeons in Switzerland due to the increased risk of bowel perforations.

In contrast, the open (Hasson) technique is characterized by the open introduction of the first trocar under direct vision [10]. The pneumoperitoneum is subsequently established through the blunt-tipped trocar. Although the open technique is a very safe method to enter the peritoneal cavity. perforating lesions have also been described by different authors, as well as in this series $[7,17]$. Those injuries may be related to the lysis of intraabdominal adhesions and perforations with the instruments used to create the minilaparotomy. whereas direct injuries from the blunt-tipped trocar appear to be rather less important.

The closed technique using the Veress needle-which is believed to be less time-consuming, less invasive, and better at preventing gas leakage at the first trocar entry site-is preferred by the majority of surgeons [3]. However, at least two comparative studies have failed to show any timesaving advantages for closed laparoscopy, and in experi- 
Table 6. Reasons for reoperation and outcome

\begin{tabular}{|c|c|c|c|c|c|c|c|c|}
\hline $\begin{array}{l}\text { Pt. } \\
\text { no. }\end{array}$ & $\operatorname{Sex}$ & $\begin{array}{l}\text { Age } \\
(\mathrm{yr})\end{array}$ & Inst. & $\begin{array}{l}\text { Surgical } \\
\text { procedure }\end{array}$ & $\begin{array}{l}\text { Affected } \\
\text { organ }\end{array}$ & Initial therapy & Reason for reoperation & Outcome \\
\hline 1 & $\mathbf{M}$ & 62 & $\mathrm{~T}$ & Herniotomy & Small bowel & $\begin{array}{l}\text { Lesion recognized i.o., } \\
\text { perforation closed }\end{array}$ & $\begin{array}{l}\text { Peritonitis (insufficient closure } \\
\text { of the initial defect) }\end{array}$ & $\begin{array}{l}\text { Reoperation } 5 x \text {, continuous } \\
\text { abdominal lavage, } \\
\text { ileostoma, hernia of the } \\
\text { abdominal wall, } \\
\text { uneventful }\end{array}$ \\
\hline 2 & $\mathrm{M}$ & 53 & $\mathrm{~T}$ & $\begin{array}{l}\text { Diagnostic } \\
\quad \text { laparoscopy }\end{array}$ & Small bowel & $\begin{array}{l}\text { Lesion not } \\
\text { recognized i.o. }\end{array}$ & Peritonitis & $\begin{array}{l}\text { Small bowel resection, } \\
\text { uneventful }\end{array}$ \\
\hline 3 & $F$ & 60 & $\mathrm{~T}$ & Cholecystectomy & Small bowel & $\begin{array}{l}\text { Lesion recognized i.o., } \\
\text { perforation closed }\end{array}$ & $\begin{array}{l}\text { Cutaneous fistula. abscess of } \\
\text { the abdominal wall (insufficient } \\
\text { closure of the initial defect) }\end{array}$ & $\begin{array}{l}\text { Small bowel resection. } \\
\text { debridement of the } \\
\text { abdominal wall, } \\
\text { uneventful }\end{array}$ \\
\hline 4 & $\mathrm{~F}$ & 59 & $\mathrm{~T}$ & Cholecystectomy & Small bowel & $\begin{array}{l}\text { Lesion not } \\
\text { recognized i.o. }\end{array}$ & Peritonitis & $\begin{array}{l}\text { Closure of the perforation, } \\
\text { uneventful }\end{array}$ \\
\hline 5 & $\mathrm{~F}$ & 76 & $\mathrm{~V}$ & Cholecystectomy & Mesentery & $\begin{array}{l}\text { Lesion recognized i.o. } \\
\text { no treatment }\end{array}$ & $\begin{array}{l}\text { Ileus due to herniation of small } \\
\text { bowel through the mesenteric } \\
\text { lesion (internal hernia) }\end{array}$ & $\begin{array}{l}\text { Reposition of the small } \\
\text { bowel, closure of the } \\
\text { mesenteric defect, } \\
\text { uneventful }\end{array}$ \\
\hline
\end{tabular}

Pt. no., patient number; M, male; F, female: Inst., offending instrument: T, trocar; V, Veress needle; i.o.. intraoperatively

enced hands, the leakage of carbon dioxide can be prevented by using a careful dissection technique $[2,16]$.

The overall incidence of vascular and visceral injuries during laparoscopy, which includes TI, NI, and other intraoperative injuries caused by different instruments (electrocautery hook, scissors, and graspers), ranges from $0.05 \%$ to $1.05 \%$ and from $0.048 \%$ to $0.35 \%$, respectively $[3,5,6,17]$. The wide range of reported incidences may reflect the use of different definitions. Furthermore, there is a tendency to underreport such complications in retrospective and multicenter studies. In our series, the overall incidence of intraabdominal complications caused by trocars and Veress needles was $0.182 \%$; vascular injuries occurred in $0.049 \%$ and visceral injuries in $0.133 \%$ of cases. There were 12 lesions after blind insertion of the first trocar (following establishment of the pneumoperitoneum) or the Veress needle; the remaining 14 lesions occurred after the open introduction of either the first trocar (Hasson technique) or the other working trocars under visual control.

There have been no prospective randomized trials comparing open vs closed establishment of the pneumoperitoneum. However, two prospective randomized trials comparing Veress needle vs direct trocar insertion without prior pneumoperitoneum showed significant advantages for the latter technique $[4,12]$. Due to the very low incidence of injuries, a large number of patients would be required to reach statistically significant differences. Therefore, most studies are either retrospective series, reviews of the published data, or smaller case series [3]. Wherry et al. reported on three access-related major bleeding complications among 10 vascular lesions (30\%) [17]. Furthermore, 11 of 29 visceral injuries $(51.7 \%)$ were caused by open-inserted trocars. Other, mostly smaller series also found intraabnominal complications after open trocar insertion, especially in cases of umbilical trocar placement $[5,6]$. In contrast, in their series and literature review, Bonjer et al. and Sigman et al. clearly showed an increased incidence of vascular and visceral injuries after closed vs open establishment of the pneumoperitoneum $[3,16]$.

Introduction of both the first trocar and the Veress needle near the umbilicus and at the suprapubic site is associated with a higher rate of perforating injuries $[5,18]$. In the current series, 17 of $26 \mathrm{TI}$ and NI were related to one of these two locations. Furthermore, epigastric trocar placement contributed to another two lesions. All of these complications (19 lacerations, $73.1 \%$ ) were due to a midline access, which seems to be more dangerous than lateral trocar or needle insertion. Lifting the abdominal wall in obese patients often increases the distance between the skin and the abdominal fascia because of the loosely attached subcutaneous adipose tissue. The Veress needle or trocar then requires increased force to enter the peritoneal cavity, thus running a risk of intraabdominal injuries. At the same time, thin patients with bowel and major retroperitoneal vessels close to the abdominal wall are also at risk of a perforating complication. Prior abdominal surgery, which is often performed through a midline laparotomy, leads to adhesions of the small and large bowel to the anterior abdominal wall, and blind insertion may cause inadvertent perforation of the adjacent hollow viscus organs. Dilated bowel loops are a common problem in cases of emergency laparoscopy and cases of adhesion- and cancer-related (peritoneal carcinomatosis) bowel obstruction, so open access is probably safer than blind puncture of the abdominal cavity in these circumstances [1].

As far as we could tell, neither the type, size, or shape of the trocar contributed to an increased risk of perforating lesions. The use of conical rather than sharp trocars may reduce the number of abdominal wall injuries, but intraabdominal lesions cannot be prevented by any type of trocar [5]. In contrast to the findings of Bonjer et al. and Zaraca et al., the open access method used in the current series failed to show any superiority over the closed establishment of the pneumoperitoneum [3, 19].

The outcome of TI and NI is strongly related to the type of anatomical structure that is injured (visceral or vascular), the immediate recognition of the lesion, and the meticulous repair, which usually necessitates a conversion to laparotomy. Hematoma formation in the abdominal cavity or the retroperitoneal space is the main clinical sign of any vas- 
cular injury, and its occurrence facilitates immediate recognition of the injury. However, the exact localization of the predominantly venous bleeding sources in the mesentery or the greater omentum may be hindered by an increased absorption of light in the presence of blood, excessive adipose tissue, and moving bowel loops. Laparoscopic or open hemostasis is achieved using bipolar current, clips, or sutures. Major vascular injuries in the retroperitoneal space are dangerous incidents, and rapid conversion is mandatory to achieve hemostasis and avoid further complications (e.g., ischemic complications, thrombosis). As with vascular injuries, lacerations of parenchymatous organs, such as the liver and spleen, are generally indicated by intraabdominal bleeding, and thus are discovered rapidly. Smaller lesions restricted to the surface of the injured organ can be managed laparoscopically.

Special attention should be paid to small bowel injuries because their recognition is often delayed; subsequently, the morbidity is markedly increased [14, 15, 18]. If there is only a slight leakage without obvious extravasation, the laceration is likely to remain unrecognized intraoperatively. Moving small bowel loops and the greater omentum tend to hide the defect and may even close the leakage temporarily. Moreover, it can be assumed that minor puncture injuries will close spontaneously without causing further complications. The postoperative development of peritonitis is an indication of severe perforating bowel injuries, and emergency reoperation is called for. In general, careful closure of the defect or segmental resection of the injured bowel requires either a conversion or an open reoperation. Septic complications due to insufficient closure at the site of bowel leakage may be deleterious for the patient. In our series, two small bowel injuries went unrecognized during the initial surgical procedure; both patients underwent open reoperation. Another two patients who had had primary closure of small bowel lesions developed intraabdominal abscess and enterocutanous fistula formation due to releakage of improperly closed small bowel defects in the further postoperative course.

\section{Conclusions}

Trocar and needle injuries are rare complications of laparoscopy (incidence, $0.18 \%$ ). Unexpected hematoma formation indicates vascular lesions, and immediate recognition of the injury facilitates the achievement of hemostasis. The diagnosis of visceral lesions-in particular, perforation of the small bowel-remains difficult; thus, delayed recognition is associated with increased morbidity. Careful access to the peritoneal cavity remains one of the most crucial steps in laparoscopic surgery. In cases of severe hemodynamic changes during the early postoperative course, bleeding complications due to TI and NI should be excluded. More- over, the development of sepsis and peritonitis 24-72 h postoperatively after laparoscopy is highly suspicious of bowel perforation, which must be excluded by emergency reintervention.

\section{References}

1. Bailey IS, Rhodes M, O'Rourke N, Nathanson L, Fielding G (1998) Laparoscopic management of acute small bowel obstruction. $\mathrm{Br} J \mathrm{Surg}$ 85: 84-87

2. Ballem RV, Rudomanski J (1993) Techniques of pneumoperitoneum. Surg Laparosc Endosc 3: 42-43

3. Bonjer HJ, Hazebroek EJ, Kazemier G, Giuffrida MC, Meijer WS, Lange JF (1997) Open versus closed establishment of pneumoperitoneum in laparoscopic surgery. Br I Surg 84: 599-602

4. Byron JW, Markenson G, Miyazawa K (1993) A randomized comparison of Verres needle and direct trocar insertion for laparoscopy. Surg Gynecol Obstet 177: 259-262

5. Champault G, Cazacu F, Taffinder N (1996) Serious trocar accidents in laparoscopic surgery: a French survey of 103,852 operations. Surg Laparosc Endosc 6: 367-370

6. Deziel DJ, Millikan KW, Economou SG, Doolas A, Ko ST, Airan MC (1993) Complications of laparoscopic cholecystectomy: a national survey of 4,292 hospitals and an analysis of 77,604 cases. Am J Surg 165: 9-14

7. Hanney RM, Carmalt HL, Merrett N, Tait N (1999) Use of the Hasson cannula producing major vascular injury at laparoscopy. Surg Endosc 13: 1238-1240 DOI: $10.1007 / \mathrm{s} 004649901235$

8. Hanney RM, Carmalt HL, Merrett N, Tait N (1999) Vascular injuries during laparoscopy associated with the Hasson technique. J Am Coll Surg 188: $337-338$

9. Hashizume M, Sugimachi K (1997) Needle and trocar injury during laparoscopic surgery in Japan. Surg Endosc 11: 1198-1201 DOI: $10.1007 / \mathrm{s} 004649900568$

10. Hasson HM (1971) A modified instrument and method for laparoscopy. Am J Obstet Gynecol 110: 886-887

11. Mac CC, Lecuru F, Rizk E, Robin F, Boucaya V, Taurelle R (1999) Morbidity in laparoscopic gynecological surgery: results of a prospective single-center study. Surg Endosc 13: 57-61 DOI: 10.1007/ s004649900898

12. Nezhat FR. Silfen SL, Evans D, Nezhat C (1991) Comparison of direct insertion of disposable and standard reusable laparoscopic trocars and previous pneumoperitoneum with Veress needle. Obstet Gynecol 78: $148-150$

13. Reddick EJ, Olsen DO (1989) Laparoscopic laser cholecystectomy: a comparison with mini-lap cholecystectomy. Surg Endosc 3: 131-133

14. Reich H (1992) Laparoscopic bowel injury. Surg Laparosc Endosc 2: 74-78

15. Sadeghi-Nejad H, Kavoussi LR, Peters CA (1994) Bowel injury in open technique laparoscopic cannula placement. Urology 43: 559-560

16. Sigman $\mathrm{HH}$, Fried GM, Garzon J, Hinchey EJ, Wexler MJ, Meakins JL, Barkun JS (1993) Risks of blind versus open approach to celiotomy for laparoscopic surgery. Surg Laparosc Endosc 3: 296-299

17. Wherry DC, Marohn MR, Malanoski MP, Hetz SP. Rich NM (1996) An external audit of laparoscopic cholecystectomy in the steady state performed in medical treatment facilities of the Deparment of De. fense. Ann Surg 224: 145-154

18. Woolcott $R$ (1997) The safety of laparoscopy performed by direct trocar insertion and carbon dioxide insufflation under vision. Aust $\mathrm{N} \mathrm{Z}$ J Obstet Gynaecol 37: 216-219

19. Zaraca F, Catarci M, Gossetti F, Mulieri G, Carboni M (1999) Routine use of open laparoscopy: 1,006 consecutive cases. J Laparoendosc Adv Surg Tech A 9: 75-80 